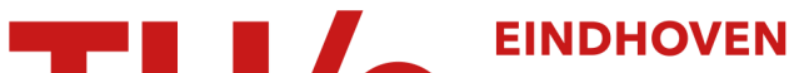 \\ UNIVERSITY OF \\ TECHNOLOGY
}

\section{Osteocyte density changes in aging and osteoporosis}

Citation for published version (APA):

Mullender, M. G., Meer, van der, D. D., Huiskes, H. W. J., \& Lips, P. (1996). Osteocyte density changes in aging and osteoporosis. Bone, 18(2), 109-113. https://doi.org/10.1016/8756-3282(95)00444-0

DOI:

10.1016/8756-3282(95)00444-0

Document status and date:

Published: 01/01/1996

\section{Document Version:}

Publisher's PDF, also known as Version of Record (includes final page, issue and volume numbers)

\section{Please check the document version of this publication:}

- A submitted manuscript is the version of the article upon submission and before peer-review. There can be important differences between the submitted version and the official published version of record. People interested in the research are advised to contact the author for the final version of the publication, or visit the $\mathrm{DOI}$ to the publisher's website.

- The final author version and the galley proof are versions of the publication after peer review.

- The final published version features the final layout of the paper including the volume, issue and page numbers.

Link to publication

\section{General rights}

Copyright and moral rights for the publications made accessible in the public portal are retained by the authors and/or other copyright owners and it is a condition of accessing publications that users recognise and abide by the legal requirements associated with these rights.

- Users may download and print one copy of any publication from the public portal for the purpose of private study or research.

- You may not further distribute the material or use it for any profit-making activity or commercial gain

- You may freely distribute the URL identifying the publication in the public portal.

If the publication is distributed under the terms of Article $25 \mathrm{fa}$ of the Dutch Copyright Act, indicated by the "Taverne" license above, please follow below link for the End User Agreement:

www.tue.nl/taverne

Take down policy

If you believe that this document breaches copyright please contact us at:

openaccess@tue.nl

providing details and we will investigate your claim. 


\title{
Osteocyte Density Changes in Aging and Osteoporosis
}

\author{
M. G. MULLENDER, ${ }^{1}$ D. D. VAN DER MEER, ${ }^{1}$ R. HUISKES, ${ }^{1}$ and P. LIPS ${ }^{2}$ \\ ${ }^{1}$ Biomechanics Section, Institute of Orthopaedics, University of Nijmegen, Nijmegen, the Netherlands \\ ${ }^{2}$ Department of Endocrinology, Academic Hospital, Free University Amsterdam, Amsterdam, the Netherlands
}

\begin{abstract}
Recently, it was suggested that osteocytes are involved in the regulation of bone remodeling. We have examined human trabecular bone of the iliac crest of fracture patients and control subjects to determine if osteoporosis is associated with changes in osteocyte density or osteocyte death. The relationships of these parameters with age was also investigated. It was found that osteocyte death was not related to age, nor was it increased in osteoporosis compared with the controls. In healthy adults ranging from 30 to 91 years, lacunar number per bone area decreases with advancing age, from about $210 / \mathrm{mm}^{2}$ to $150 / \mathrm{mm}^{2}$. Significantly higher lacunar and osteocyte numbers per bone tissue volume were found in osteoporotics than in controls $\left(17,100\right.$ lacunae/ $\mathrm{mm}^{3}$ and 13,300 osteocytes $/ \mathrm{mm}^{3}$ vs. 12,900 lacunae $/ \mathrm{mm}^{3}$ and 10,500 osteocytes $/ \mathrm{mm}^{3}$, respectively), whereas lacunar area was significantly reduced in osteoporotics (from $44.1 \mu \mathrm{m}^{3}$ to $39.1 \mathrm{\mu m}^{2}$ ). These findings are compatible with the hypothesis that, in osteoporosis, osteoblasts produce less bone per cell. This can in turn explain the reduced wall thickness, which has previously been described as characteristic for osteoporosis. (Bone 18:109-113; 1996)
\end{abstract}

Key Words: Osteocyte; Trabecular bone; Osteocyte lacunar number; Osteocyte lacunar size; Osteoporosis.

\section{Introduction}

Bone is a dynamic tissue undergoing continuous renewal. The mechanical integrity of bone is ensured by removal of bone and subsequent replacement by new bone. After the age of 25-30 years, a slightly negative balance between bone resorption and formation may cause progressive bone loss. Usually, mechanical integrity is maintained. However, in osteoporosis, excessive bone loss and loss of structural elements can lead to mechanical failure. ${ }^{24}$ As turnover is highest in cancellous bone, osteoporosis becomes manifest particularly in regions where the trabecular architecture is of great structural importance such as, for instance, in the vertebral body and the femoral trochanter. The cause of osteoporosis is sought in a disturbed regulation of the bone remodeling process. ${ }^{8}$ It is well established that mechanical usage is essential for the maintenance of bone. Hence, several investigators suggested that osteoporosis is possibly caused by an inadequate appraisal of the mechanical load in bone, because the changes in bone occurring in osteoporosis are similar to changes

Address for correspondence and reprints: R. Huiskes, Ph.D., Biomechanics Section, Institute of Orthopaedics, University of Nijmegen, P.O. Box 9101, 6500 HB Nijmegen, the Netherlands. resulting from disuse. ${ }^{10,25}$ Yet, the normal regulation of bone remodeling has still to be unraveled. The regulation of the remodeling sequence and the coupling mechanism between the activity of osteoclasts and the activation of osteoblasts are still unknown.

Recently, it was suggested that osteocytes play a role in the regulation of bone remodeling. It was hypothesized that osteocytes regulate the recruitment of basic multicellular units (BMUs) in response to mechanical stimuli, ${ }^{1,3,15,17}$ and that they play a role in the modulation of osteoblast activity and the recruitment of osteoblasts which differentiate into osteocytes. ${ }^{18} \mathrm{~A}$ number of experiments (in vivo and in vitro) showed that osteocytes respond to mechanical loading with an increased production of factors which are known to affect bone turnover. ${ }^{14.15}$ Mullender et al. ${ }^{20}$ and Mullender and Huiskes, ${ }^{19}$ using a computer simulation model, have shown that trabecular modeling patterns due to mechanical stimuli can be explained quantitatively by assuming osteocytes to act as strain-sensing cells in a regulatory process. They showed that osteocyte density and range of influence, i.e., the distance from which they can affect BMU activity, may have distinct effects on the trabecular morphology. They also showed that a reduced sensitivity of osteocytes to mechanical load caused bone loss in a similar way as did disuse.

The above hypotheses and findings have led us to the hypothesis that a disturbance in the regulation of bone remodeling in osteoporosis may be associated with a lack of osteocytes or inefficacy of function. To investigate this hypothesis, we have determined the number of osteocytes per bone area and volume and the fraction of empty lacunae, as an indicator of osteocyte death, in osteoporotic patients and control subjects.

\section{Materials and Methods}

\section{Subjects}

The osteoporosis group consisted of 14 patients ( 4 men and 10 women, age $65.2 \pm 7.2$ years [mean \pm SD]) with each at least one vertebral crush fracture (collapsed vertebra), and 23 patients ( 9 men and 14 women, age $73.6 \pm 11.3$ ) with hip fractures. Transiliac biopsies were taken from all patients. Iliac crest bone samples from 25 autopsy subjects (sudden death in previously healthy persons) and 4 patients who received cosmetic or orthopedic surgery unrelated to bone disease were obtained for the control group ( 24 men and 5 females, age $57.0 \pm 18.5$ years). None of the control group had a history of any disease known to predispose to osteoporosis, and neither control subjects or patients received drugs with known effects on bone. 


\section{Histology}

The undecalcified biopsies were embedded in methylmetacrylate, sectioned $(5 \mu \mathrm{m})$ and stained with Goldner's trichrome. Histomorphometry was performed on the trabecular bone of two sections per biopsy. Microscopic fields were sampled in equally spaced rows by moving the specimens in equally sized steps such that the total specimen area was covered. A Zeiss integrating eyepiece was used for the measurement of trabecular bone volume (BV/TV) by counting the number of hits and the number of intersections. More extensive histomorphometric data of both groups were published in a different study. ${ }^{31}$

In addition, the number of lacunae occupied by osteocytes and the number of empty lacunae per bone area were measured in trabecular bone. Osteocytes are colored red and are readily visible in the bone matrix. Empty lacunae were defined as lacunae without any visible remnant of a cell inside. These measurements were performed using a Zeiss microscope in conjunction with a digital image analysis system (Videoplan). Twenty fields were sampled in two sections per subject ( $\times 25$ objective) by moving the specimen in equally sized steps in $x$ and $y$ directions. In this way, a total bone area of approximately $1 \mathrm{~mm}^{2}$ per subject was measured to determine lacunar and osteocyte numbers. The investigator had no knowledge about the origin of the sections. From these measurements, the following parameters were deduced: the fraction of empty lacunae (number of empty lacunae/ total number of lacunae); the total number of lacunae per bone area (N.Lc/B.Ar); and the number of lacunae occupied by osteocytes per bone area (N.Ot/B.Ar)

The measured number of osteocyte lacunae per area depends on both the number of lacunae per volume and the average lacunar size. Because we wanted to determine if differences in lacunar number per bone area between controls and osteoporotics are due to differences in lacunar size, or to differences in lacunar number per bone volume, we also measured lacunar area (Lc.Ar) as an indicator of lacunar size. These measurements were made by outlining at least 75 lacunae per section in randomly selected fields, totaling at least 150 lacunae per subject $(\times 100$ oil immersion objective).

The measured parameters N.Ot/B.Ar, N.Lc/B.Ar, and Lc.Ar were used to estimate the number of osteocytes per bone volume (N.Ot/BV) and the number of lacunae per bone volume (N.Lc/ BV). First, the measured lacunar area was used to calculate an average "osteocyte radius," $R$. Assuming that osteocytes have a spherical shape, the measured Lc.Ar is equal to $\mathrm{Lc} . \mathrm{Ar}=2 / 3 \pi R^{2}$, for infinitely thin sections. If the equation is corrected for the section thickness $(t)$, and if it is further assumed that $k$ is the thickness of the smallest part of a cell which must be included in the section for its identification, the equation is modified to:

$$
\text { Lc. Ar }=\pi\left(R^{2}-\frac{(R-k)^{3}}{3(R-k+1 / 2 t)}\right) .
$$

As this equation is not easily inverted to calculate $R$, it was estimated by fitting $R$ to obtain the measured Lc.Ar with a maximal error of $0.005 \mu \mathrm{m}{ }^{2}$ This is only a rough estimate of $R$, because osteocytes in fact have an elliptical shape.

The number of osteocytes and lacunae per volume were calculated according to:

$$
\begin{aligned}
& \text { N.Ot/BV }=\frac{\text { N.Ot/B.Ar }}{2 R+t-2 k}, \\
& \text { N.Lc/BV }=\frac{\text { N.Lc/B.Ar }}{2 R+t-2 k},
\end{aligned}
$$

where $k$ and $t$ are the same factors as above. ${ }^{27} \mathrm{~A}$ section thickness of $t=5.0 \mu \mathrm{m}$ and a value of $k=0.2 \mu \mathrm{m}$ was used.

\section{Statistical Analysis}

Averages and standard deviations of all measured parameters were determined per group. The reproducibility of the method for measuring lacunar density and size was assessed using the coefficient of variation. These parameters were measured four times in six sections by one observer and were again measured by a second investigator. To increase reproducibility, all measurements were conducted by the same investigator. Correlations between parameters and age were examined by linear regression analyses. Differences between groups were tested using the two-tailed Student's $t$-test. To exclude effects of age differences, only subjects older than 55 years were used for the comparison between the control group and the osteoporosis group. However, it should be noted that the group of hip fracture patients was still older than the control group.

\section{Results}

The values for reproducability are given in Table 1 . The mean values and standard deviations of all measured parameters are given in Table 2. No differences in parameter values were found between males and females within each group. BV/TV was significantly decreased in the osteoporotic patients relative to the control group older than 55 years. The BV/TV of two control subjects could not be reliably measured because the specimen sizes were too small. The N.Lc/B.Ar and also the N.Ot/B.Ar were significantly higher in younger controls than in older controls. In addition, the N.Le/B.Ar and N.Ot/B.Ar were significantly higher in the hip fracture and vertebral fracture groups relative to the older control group (Figure 1). Lc.Ar was significantly smaller in hip fracture patients and in the combined osteoporosis group than in the older control subjects (Figure 2). As the lacunar size was smaller in the osteoporosis group relative to the older control group, the differences in number of lacunae and osteocytes per bone volume were even more pronounced than the differences between numbers per bone area. The N.Lc/ $\mathrm{BV}$ and N.Ot/BV were also significantly higher in the younger controls in comparison with the older controls. The fraction of empty lacunae did not differ significantly between groups.

The relationships between several parameters and age are presented in Table 3. In the control group, the number of lacunae and osteocytes per bone area and per bone volume declined significantly with advancing age (Figure $l a$ and $b$ ). The fraction of empty lacunae and lacunar area were not significantly related to age. No significant relationships between age and other parameters were found in the osteoporosis group.

Table 1. Coefficient of variation (\%) for repeated measurements

\begin{tabular}{lcc}
\hline & Intraobserver & Interobserver \\
\hline Lacunac per bone area & 4.5 & 3.5 \\
Osteocytes per bone area & 4.8 & 5.3 \\
Percentage of empty lacunae & 3.9 & 7.6 \\
Lacunar area & 14.6 & 23.1 \\
\hline
\end{tabular}

"Reproducibility of lacunar numbers, numbers of osteocytes, and fraction of empty lacunae are good, but measurements of osteocyte size show large variation. 
Table 2. Subject data and histomorphometric parameters in control subjects and osteoporotic patients (average values and standard deviations)

\begin{tabular}{|c|c|c|c|c|c|c|}
\hline & \multicolumn{3}{|c|}{ Controls } & \multicolumn{3}{|c|}{ Osteoporotic patients $>55$ years } \\
\hline & $\leq 55$ years & $>55$ years & Combined & Hip fract. & Vert. fract. & Combined \\
\hline Male & 12 & 12 & 24 & 8 & 2 & 10 \\
\hline Female & - & 5 & 5 & 14 & 10 & 24 \\
\hline Age (years) & $39.0 \pm 7.7^{b}$ & $69.7 \pm 12.0$ & $57.0 \pm 18.5$ & $79.7 \pm 9.3^{\mathrm{a}}$ & $67.6 \pm 4.7$ & $75.4 \pm 9.9$ \\
\hline BV/TV $(\%)$ & $18.0 \pm 6.3$ & $16.8 \pm 5.9^{\mathrm{c}}$ & $17.4 \pm 6.1$ & $12.5 \pm 4.1^{\mathrm{a}}$ & $8.4 \pm 4.2^{b}$ & $11.0 \pm 4.5^{\mathrm{b}}$ \\
\hline N.Lc/B.Ar $\left(\mathrm{mm}^{-2}\right)$ & $206.5 \pm 29.2^{\mathrm{a}}$ & $165.7 \pm 38.3$ & $182.6 \pm 39.9$ & $203.0 \pm 29.7^{a}$ & $228.9 \pm 28.2^{b}$ & $212.1 \pm 31.4^{\mathrm{b}}$ \\
\hline N.Ot/B.Ar $\left(\mathrm{mm}^{-2}\right)$ & $172.8 \pm 34.9^{\mathrm{a}}$ & $135.1 \pm 38.0$ & $150.7 \pm 40.7$ & $158.3 \pm 23.6^{\mathrm{a}}$ & $176.0 \pm 21.6^{\mathrm{a}}$ & $164.5 \pm 24.2^{a}$ \\
\hline Fract. empty lacunae & $0.17 \pm 0.08$ & $0.19 \pm 0.10$ & $0.18 \pm 0.09$ & $0.22 \pm 0.05$ & $0.22 \pm 0.06$ & $0.22 \pm 0.05$ \\
\hline Lc. Ar $\left(\mu \mathrm{m}^{2}\right)$ & $47.3 \pm 5.8$ & $44.1 \pm 7.3$ & $45.5 \pm 6.8$ & $38.5 \pm 4.1^{b}$ & $40.0 \pm 6.2$ & $39.1 \pm 4.9^{\mathrm{b}}$ \\
\hline N.Lc/BV $\left(10^{3} \mathrm{~mm}^{-3}\right)$ & $15.6 \pm 2.0^{\mathrm{a}}$ & $12.9 \pm 3.2$ & $14.0 \pm 3.0$ & $16.5 \pm 2.5^{b}$ & $18.4 \pm 2.2$ & $17.1 \pm 2.5^{\mathrm{b}}$ \\
\hline N.Ot/BV $\left(10^{3} \mathrm{~mm}^{-3}\right)$ & $13.1 \pm 2.4$ & $10.5 \pm 3.0$ & $11.6 \pm 3.0$ & $12.8 \pm 1.9^{b}$ & $13.7 \pm 2.2^{\mathrm{a}}$ & $13.3 \pm 2.0^{\mathrm{b}}$ \\
\hline
\end{tabular}

${ }^{\text {a }}$ Significantly different from the control group $>55$ years $(p<0.05)$.

${ }^{b}$ Significantly different from the control group $>55$ years $(p<0.01)$.

${ }^{\mathrm{c}}$ Measurements of two subjects discarded $(n=15)$.

\section{Discussion}

Recently, it was suggested that osteocytes are involved in the regulation of bone remodeling. ${ }^{1,3,15,17-20}$ Furthermore, it was proposed that the incorporation of osteoblasts into the matrix (i.e., the inclusion of osteocytes) is a highly regulated process in which the preosteocytes themselves and osteocytes already incorporated are actively involved. ${ }^{17.21-23}$ Therefore, it is plausible that changes or disturbances in (pre-)osteocyte function also affect osteocyte morphology and osteocyte number. If we assume that osteocytes do indeed play a central role in the regulation of bone turnover, a disturbance of this regulatory process may be caused by disturbances in osteocyte presence or viability. The questions investigated in this study were: Does osteocyte number and size differ between osteoporotic patients compared with controls, and does excessive osteocyte death occur in osteoporosis? In addition, we have investigated whether osteocyte death, osteocyte density, and lacunar density are related to age.

Few investigators have actually measured osteocyte density. Hobdell and Howe ${ }^{12}$ found that the average volume of bone matrix associated with one osteocyte lacunae was $0.000077 \mathrm{~mm}^{3}$ in human adult lamellar bone. This is equivalent to $13,000 \mathrm{~mm}^{3}$ lacunae per bone volume. Sissons and $\mathrm{O}^{\prime} \mathrm{Connor}^{27}$ report values for N.Lc/BV between 13,900 and $19,400 \mathrm{~mm}^{-3}$ in human cortical bone, depending on the type of sections used. The most accurate method to determine numbers of cells per volume is known as the disector method. ${ }^{11,30}$ However, this method requires serial sectioning of the specimen. As our specimens were already processed for the purpose of histomorphometric analysis, it was not possible to use the disector method. Instead, we measured lacunar area which is a direct estimate of lacunar volume and the number of osteocytes per bone area, which is a method generally accepted for other cell types such as osteoblasts or osteoclasts. Although our calculated figures for osteocyte and lacunar numbers per bone volume only give an estimate of the actual figures, our figures (N.Lc/BV ranging from 12,900 to $18,400 \mathrm{~mm}^{-3}$ ) agree very well with the values reported earlier.

Significant differences were found in osteocyte density and lacunar density between osteoporotics and controls (55 years). Lacunar and osteocyte number per bone area were significantly
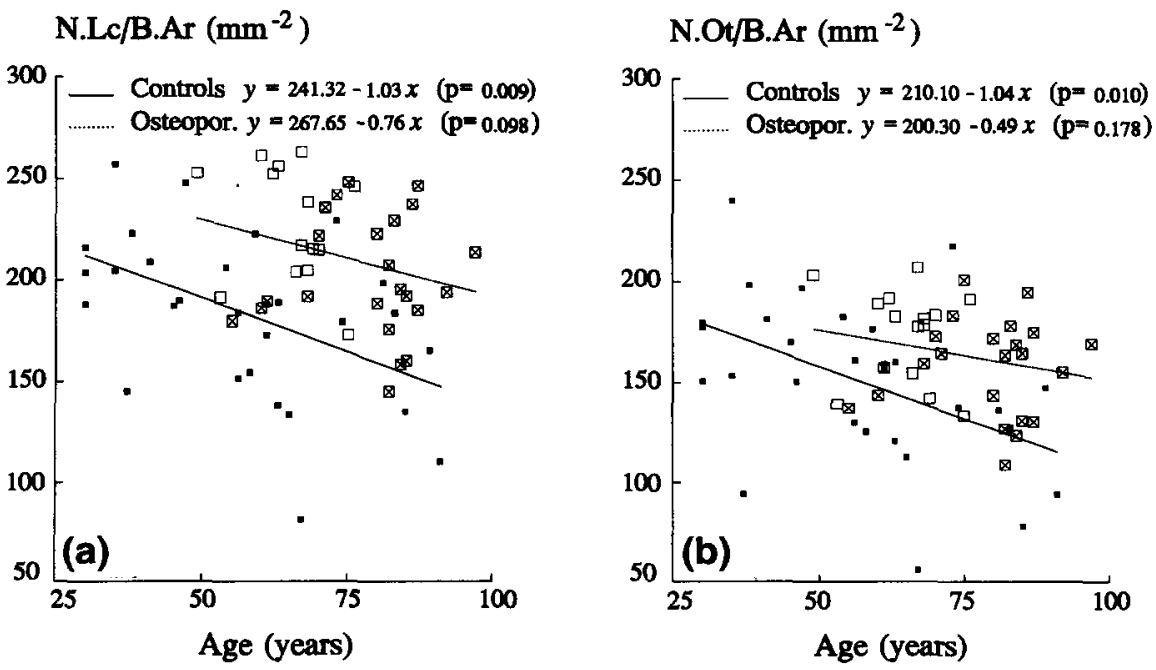

Figure 1. The relationships between age and the number of lacunae per bone area (a) and the number of osteocytes per bone area (b). In the control group $(\square)$, the number of lacunae as well as the number of osteocytes per bone area decrease with age. In both groups of fracture patients (vert. fract., $\square$; hip fract., $\bigotimes$ ), the numbers of lacunae and osteocytes per bone area are significantly increased compared with controls of similar ages. 
Table 3. Linear regression equations and correlation coefficients of several parameters in relation to age

\begin{tabular}{llllll}
\hline$x$ & \multicolumn{1}{c}{$y$} & Group & $n$ & Regression equation & Correlation coefficient \\
\hline Age (years) & N.Lc/BAr $\left(\mathrm{mm}^{-2}\right)$ & Controls & 29 & $y=241.32-1.03 x^{\mathrm{b}}$ & $-0.48^{\mathrm{b}}$ \\
& & Osteoporotics & 37 & $y=267.65-0.76 x$ & -0.27 \\
Age (years) & N.Ot/BAr $\left(\mathrm{mm}^{2}\right)$ & Controls & 29 & $y=210.10-1.04 x^{\mathrm{b}}$ & $-0.47^{\mathrm{b}}$ \\
& & Osteoporotics & 37 & $y=200.30-0.49 x$ & -0.23 \\
Age (years) & N.Lc/BV $\left(10^{3} \mathrm{~mm}^{-3}\right)$ & Controls & 29 & $y=18.00-0.07 x^{\mathrm{a}}$ & $-0.42^{\mathrm{a}}$ \\
& & Osteoporotics & 37 & $y=21.16-0.06 x$ & -0.25 \\
Age (years) & N.Ot/BV $\left(10^{3} \mathrm{~mm}^{-3}\right)$ & Controls & 29 & $y=15.66-0.07 x^{\mathrm{a}}$ & $-0.44^{\mathrm{a}}$ \\
& & Osteoporotics & 37 & $y=15.83-0.04 x$ & -0.20 \\
\hline
\end{tabular}

${ }^{\mathrm{a}} p<0.05 ;{ }^{\mathrm{b}} p<0.01$.

increased in osteoporotic patients relative to controls. A higher number of osteocyte lacunae per bone area may be due to a higher number of lacunae per bone volume and/or to enlarged lacunar sizes. ${ }^{27,30}$ Enlarged osteocyte lacunae have been reported in osteoporotic patients ${ }^{34}$ and in calcium-deficient rats. ${ }^{28.29}$ However, in this study we found that the lacunar area was smaller in the osteoporosis group compared with controls. Hence, the differences in numbers of lacunae and osteocytes per bone volume were even more pronounced than these differences in numbers per bone area. These results suggest that, in osteoporosis, less bone volume was produced per osteocyte. There are three possible explanations for this phenomenon: (1) a higher percentage of the bone forming osteoblasts is embedded as osteocytes, whereas the average activity or longevity is unchanged; (2) the bone forming activity of osteoblasts is reduced; and (3) the average life-span of osteoblasts is shorter. The latter two explanations seem to be the most likely ones, because they are compatible with the findings that bone formation and mean wall thickness are decreased in osteoporotic patients compared with normals. ${ }^{4,6}$ Eriksen and Kassem ${ }^{7}$ even state that the most marked difference between osteoporotic and normal women is a considerable reduction of mean wall thickness in osteoporotics. While Eriksen and Kassem ${ }^{7}$ suggested this to be due to a reduced osteoblastic vigor, Lips et al. ${ }^{16}$ explained the decrease in mean

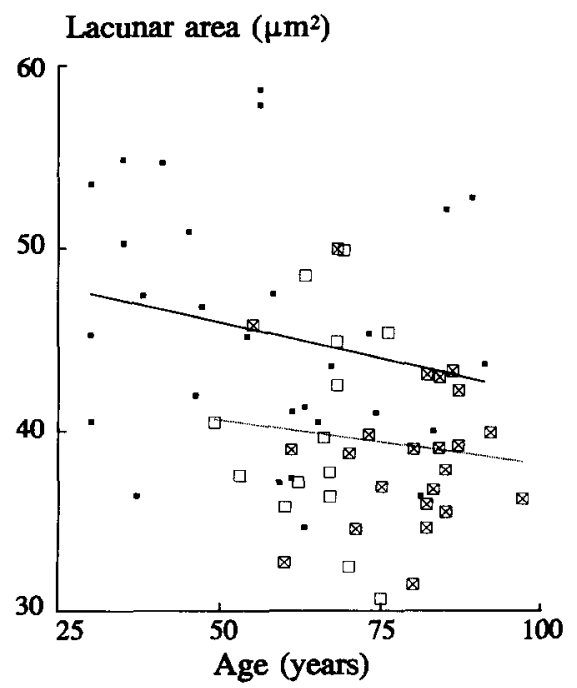

Figure 2. The lacunar area is given as a function of age. Although the regressions are not significant, they illustrate that the lacunar area is reduced in osteoporosis compared with the control group (control, vert. fract., $\square$; hip fract., 冈). Regressions (---) controls $y=49.96-$ $0.08 x(p=0.26)$; and (...) osteoporotics $y=43.11-0.05 x(p=0.46)$. wall thickness by a decreased longevity of the osteoblasts. To distinguish between these two hypotheses, Shih et al. ${ }^{26}$ investigated the relationship between bone formation rate and osteoblast surface. They found that, although bone formation rate is reduced in women with osteoporosis compared to normal women, the relationship was similar in both groups. This implies that, in osteoporotics, either fewer osteoblasts are recruited or that active osteoblasts are transformed quicker into less active ones. Our results suggest that the bone forming capacity per cell is reduced, which is compatible with the latter explanation of Shih et al. ${ }^{26}$ Furthermore, a decreased longevity of osteoblasts may explain that more are incorporated as osteocytes per bone volume. The reduced lacunar size may also indicate a history of reduced activity of these cells.

The relationship between age and osteocyte density in humans has (to our knowledge) not yet been reported. A significant decrease of osteocyte and lacunar density associated with a (not significant) decrease in lacunar size was found with increasing age in healthy adults from 30 to 91 years of age. This decrease was also observed in the osteoporosis group, but it was not significant due to the smaller age range. Some controversy exists in these results. As Lips et al. ${ }^{16}$ showed that mean wall thickness in trabecular bone decreases with aging, it would be expected that osteocyte number increases with increasing age and that this increase is more pronounced in osteoporosis. However, it was found that osteocyte density decreases with age. Hence, it seems that two different phenomena occur at the same time. To explain these phenomena, it is necessary to investigate the relationship between osteocyte number and remodeling activity more closely.

The percentage of empty lacunae was used as an indicator of osteocyte death. Nonviable osteocytes can stain normally up to 16 weeks, ${ }^{13}$ but a gradual loss of osteocytes will be reflected by an increase of empty lacunae. It is possible that lacunae appear to be empty due to sectioning artifacts. However, this is very unlikely because the bone is undecalcified and the cellular processes of osteocytes are integrated within the bone matrix. Furthermore, if artifacts occur, it is assumed that they occur equally in both control and osteoporosis groups such that differences in the number of empty lacunae between the two groups will still be detected. The percentage of empty lacunae varied from $5 \%$ to $40 \%$ in all subjects. No significant correlation was found between the percentage of empty lacunae and age in both the control and the osteoporosis groups. Similar results were found by Baud and Auil ${ }^{2}$ who looked at bone from the mandible. In contrast, Wong et al. ${ }^{32.33}$ observed a loss of viable osteocytes in the femoral head with increasing age and Frost $^{9}$ also found that the percentage empty lacunae increased with age. Dunstan et al. ${ }^{5}$ showed that the occurrence of osteocyte death with age depends strongly on the location of measurement. They found that osteocyte death did increase with age in the femoral head but did not 
increase in the second lumbar vertebrae. They suggested that bone with a constant high viability is remodeled at a higher rate, and thus bone is replaced before the osteocytes have a chance to die.

The fraction of empty lacunae was not significantly elevated in osteoporosis compared with controls. Hence, it seems that osteoporosis is not associated with increased osteocyte death, which challenges the hypothesis that mechanical load is appraised inadequately due to increased osteocyte death. However, the hypothesis that osteocytes are less sensitive to mechanical stimuli still needs to be investigated.

Acknowledgment: This project was partly sponsored by the Netherlands Foundation for Research (NWO, Division of Medical Research) and by Procter and Gamble Pharmaceuticals, Cincinnati, $\mathrm{OH}$. The authors thank Professor Dr. E. H. Burger from the Academic Center for Dentistry Amsterdam, Department of Oral Cell Biology, for her valuable suggestions and for granting the use of equipment from her department.

\section{References}

1. Aarden, E. M., Burger, E. H., and Nijweide, P. J. Function of osteocytes in bone. J Cell Biochem 55:287-299; 1994.

2. Baud, C. A. and Auil, E. Osteocyte differential count in normal human alveolar bone. Acta Anat 78:321-327; 1971 .

3. Cowin, S. C., Moss-Salentijn, L., and Moss, M. L. Candidates for the mechanosensory system in bone. J Biomech Eng 113:191-197; 1991.

4. Darby, A. J. and Meunier, P. J. Mean wall thickness and formation periods of trabecular bone packets in idiopathic osteoporosis. Calcif Tissue Int 33:199$204 ; 1981$.

5. Dunstan, C. R., Somers, N. M., and Evans, R. A. Osteocyte death and hip fracture. Calcif Tissue Int 53(suppl. 1):S113-S117; 1993.

6. Eriksen, E. F., Hodgson, S. F., Eastell, R., Cedel, S. L., O'Fallon, W. M., and Riggs, B. L. Cancellous bone remodeling in type I (postmenopausal) osteoporosis: quantitative assessment of rates of formation, resorption, and bone loss at tissue and cellular levels. J Bone Miner Res 5:311; 1990.

7. Eriksen, E. F. and Kassem, M. The cellular basis of bone remodeling. Triangle, Sandoz Journal of Medical Science 31:45-57; 1992.

8. Eriksen, E. F., Langdahl, B., and Kassem, M. The cellular basis of osteoporosis. Spine State of the Art Reviews 8:23-62; 1994.

9. Frost, H. M. In vivo osteocyte death. J Bone Jt Surg 42-A:138-143; 1960

10. Frost, H. M. Vital biomechanics: proposed general concepts for skeletal adaptations to mechanical usage. Calcif Tissue Int 42:145-156; 1988.

11. Gundersen, H. J. G. Steriology of arbitrary particles. J Microsc 143:3-45; 1986.

12. Hobdell, M. H., and Howe, C. E. Variation in bone matrix volume associated with osteocyte lacunae in mammalian and reptilian bone. Israel $\mathbf{J}$ Med Sci $7: 492-493 ; 1971$.

13. Kenzora, J. E., Steele, R. E., Yosipovitch, Z. H., and Glimcher, M. J. Experimental osteonecrosis of the femoral head in adult rabbits. Clin Orthop 130:8; 1978.

14. Klein-Nulend, J., Van der Plas, A., Semeins, C. M., Ajubi, N. E., Frangos, J. A., Nijweide, P. J., and Burger, E. H. Sensitivity of osteocytes to biomechanical stress in vitro. FASEB J 9:441-445; 1995.

15. Lanyon, L. E. Osteocytes, strain detection, bone modeling and remodeling. Calcif Tissue Int 53(suppl.1):S102-S106; 1993.
Osteocyte density changes in aging and osteoporosis

16. Lips, P., Coupron, P., and Meunier, P. J. Mean wall thickness of trabecular bone packets in the human iliac crest: changes with age. Calcif Tissue Res 26:13-17; 1978 .

17. Marotti, G., Cané, V., Palazzini, S., and Palumbo, C. Structure-function relationships in the osteocyte. Ital J Miner Electrolyte Metab 4:93-106; 1990.

18. Marotti, G., Ferretti, M., Muglia, M. A., Palumbo, C., and Palazzini, S. A quantitative evaluation of osteoblast-osteocyte relationships on growing endosteal surface of rabbit tibiae. Bone 13:363-368; 1992.

19. Mullender, M. G. and Huiskes, R. A proposal for the regulatory mechanism of Wolff's law. J Orthop Res 13:503-512; 1995.

20. Mullender, M. G., Huiskes, R., and Weinans, H. A physiological approach to the simulation of bone remodeling as a self-organizational control process [technical note] J Biomech 27:1389-1394; 1994.

21. Nefussi, J. R., Sautier, J. M., Nicolas, V., and Forest, N. How osteoblasts become osteocytes: A decreasing matrix forming process. J Biol Buccale $19: 75-82 ; 1991$.

22. Palumbo, C., Palazzini, S., and Marotti, G. Morphological study of intercellular junctions during osteocyte differentiation. Bone 11:401-406; 1990.

23. Palumbo, C., Palazzini, S., Zaffe, D., and Marotti, G. Osteocyte differentiation in the tibia of newborn rabbit: an ultrastructural study of the formation of cytoplasmic processes. Acta Anat 137:350-358; 1990.

24. Parfitt, A. M., Mathews, C. H. E., Villanueva, A. R., and Kleerekoper, M. Relationships between surface, volume, and thickness of iliac trabecular bone in aging and osteoporosis. J Clin Invest 72:1396-1409; 1983.

25. Rodan, G. A. Mechanical loading, estrogen deficiency, and the coupling of bone formation to bone resorption. J Bone Miner Res 6:527-530; 1991.

26. Shih, M. S., Cook, M. A., Spence, C. A., Palnitkar, S., McElroy, H., and Parfitt, A. M. Relationship between bone formation rate and osteoblast surface on different subdivisions of the endosteal envelope in aging and osteoporosis. Bone 14:519-521; 1993.

27. Sissons, H. A. and $O^{\prime}$ Connor, P. Quantitative histology of osteocyte lacunae in time normal human cortical bone. Calcif Tissue Res 22(suppl. 1):530-533; 1977.

28. Sissons, H. A., Kelman, G. J., Ling, L., Marotti, G., Canè, V., and Muglia, M. A. A light and scanning electron microscopic study of osteocyte activity in calcium-deficient rats. Calcif Tissue Int 46:33-37; 1990.

29. Sissons, H. A., Kelman, G. J., and Marotti, G. Mechanisms of bone resorption in calcium-deficient rats. Calcif Tissue Int 36:711-721; 1984

30. Sterio, D. C. The unbiased estimator of number and sizes of arbitrary particles using the disector. J Microsc 134:127-136; 1984.

31. Uitewaal, P. J. M., Lips, P., and Netelenbos, J. C. An analysis of bone structure in patients with hip fracture. Bone Miner 3:63-73; 1987.

32. Wong, S. Y. P., Kariks, J., Evans, R. A., Dunstan, C. R., and Hills, E. The effect of age on bone composition and viability in the femoral head. $J$ Bone $\mathbf{J t}$ Surg 67A:274-283; 1985.

33. Wong, S. Y. P., Evans, R. A., Needs, C., Dunstan, C. R., Hills, E., and Garvan, J. The pathogenesis of osteoarthritis of the hip. Clin Orthop Rel Res 214:305$312 ; 1987$

34. Wright, P. H., Jowsey, J. O., and Robb, R. A. Osteocyte lacunar area in normal bone, hyperparathyroidism, renal disease, and osteoporosis. Surg Forum 29:558-559; 1978.
Date Received: June 21, 1995

Date Revised: September 8, 1995

Date Accepted: October 6, 1995 